\title{
Roadblock on the Way of Disabled Students in the Higher Education
}

\author{
Aditi Pandey \\ Department of Education, The Maharaja Sayajirao University of Baroda, Vadodara, Gujarat-390002, India
}

"aditipandeymsu@gmail.com (Corresponding Author)

\section{ARTICLE INFORMATION}

Received: January 28, 2021

Revised: July 26, 2021

Accepted: August 02, 2021

Published Online: September 29, 2021

Keywords:

Disabled students, Higher education,

Roadblocks, RPwD

\begin{abstract}
The development of any nation depends on its citizens. Every citizen has their contribution to the development of a nation even the disabled person. They also have an equal rights to get a higher education. Higher education increases the chance of employability, thus, affirming dignified life for persons with disabilities. As per Census 2011, in India, out of the $121 \mathrm{Cr}$ population, about $2.68 \mathrm{Cr}$ persons are 'disabled' which is $2.21 \%$ of the total population. But it has been seen that very few of these people reach higher education. According to census 2011, 61\% of the disabled children aged 5-19 years are attending an educational institution, 12\% attended educational institutions earlier while $27 \%$ never attended educational institutions. That makes the author think and ask about how our higher education institutions are accessible for disabled students. How inclusive are our higher education institutions? In the light of the above-mentioned problems the present paper has discussed the education of children with special needs in higher education specifically with respect to visual impairment, hearing impairement, locomotor disability, and speech-related impairment. The discussion starts with what all kind of legal provisions and reservations which are there for them in higher education and how many are utilized and used by them. What all things are there in the new education policy for them specifically in higher education, whether their needs have been realized in detail or it has been just touched superficially and at the end, few suggestions related to all these issues have been discussed.
\end{abstract}

\section{Introduction}

The world is evolving with the rapid speed where being a high school graduate doesn't open up the doors to many rewarding careers as it did in past generations. Now if one wants to cope up with the speed of change one has to get into higher education. Higher education not only assures employability but also trains one to think analytically and critically. It makes a person a wellinformed and aware citizen who can contribute to the nation's development and economy. The development of any nation depends on its citizens. Each citizen has their contribution to the development of a nation even the person with a disability whose contribution cannot be ignored. They also have equal rights to get into higher education. Higher education increases the chance of employability, thus, affirming dignified life for persons with disabilities. RPwD act 2016 has defined "person with disability" as a person with long-term physical, mental, intellectual, or sensory impairment which, in interaction with barriers, hinders his full and effective participation in society equally with others. Thus it should be the duty of the HEI to remove these barriers as much as possible. As per Census 2011, in India, out of the $121 \mathrm{Cr}$ population, about 2.68 Cr persons are 'disabled' which is $2.21 \%$ of the total population. But it has been seen that very few of these people reach higher education.

In such a situation the author is compelled to ask if this is the situation then how can equal and justified participation from these sections of people be assured towards national development. It is evident that very few are reaching higher education. Now the question is what facilities and support they are being provided in higher education. They reach by fighting all the odds to reach higher education. But here also the journey is not easy for them besides having physical disabilities and challenges they have to face, many social, psychological, and emotional challenges as well. Recently there was news that Meenu Mani, a person with cerebral palsy and a wheelchair user, sought admission to MSW in Delhi University. Her request for a change of exam centre owing to its inaccessibility 
was conceded. However, the new centre, too, was located in a basement to which a staircase had to be negotiated. In another case, the JNU administration failed in providing Munesh, a visually impaired student, with prescribed texts in Braille/audio formats. It also rejected his request for the mandated scribe and forced him to write both the sessional and end-semester exams on his own (Nagarajan, 2019). Although these are not the only issues other than these, there are various issues that need to be pondered upon. Thus in the present paper the author tried to find out how our higher education institutions are inclusive with respect to PwD students. In the light of the above-mentioned problems the present paper has discussed the education of PwD students in higher education specifically with respect to visual, hearing impaired, locomotor disabled and speech-related impairment.

\section{Status of Disabled Children in Higher Education}

As per Census 2011, in India, out of the $121 \mathrm{Cr}$ population, about $2.68 \mathrm{Cr}$ persons are 'disabled' which is $2.21 \%$ of the total population. Among the disabled in the age group $20-39$ years, $22 \%$ have a disability in movement and $18 \%$ have a disability in hearing. $6 \%$ have multiple disabilities, $8 \%$ in speech, and $15 \%$ in seeing. According to Census 2011, of the total disabled population, nearly 55\% (1.46 Cr.) are literate. Among the total disabled persons, $45 \%$ are illiterates and only $13 \%$ of the disabled population has matric/ secondary education but are not graduates and $5 \%$ are graduates and above. After seeing the percentage of illiterates it can be surely said that such a huge number of populations cannot even be utilized. It's a big loss of human capital and a big matter of concern. Here the question arises that besides having SSA and RTE, why did such a big percentage of people even not attend the educational institution? If we will see particularly the enrolment of PwD students particularly in higher education it is very less. According to the AISHE report, 2020 estimated state-wise total enrollment in higher education is 38.5 Million of which 92,831 PwD students were enrolled in higher education against 85,877 in 2019. If we compare this number with the other disadvantaged group it is the least among all which clearly shows that very less number of these people reaches to the higher education and their number also over the years is not increasing significantly. The enrolment was found to be highest in Uttar Pradesh 18,050 that too because there is a university particularly established for specifically PWD students by Jagadguru Ramanandacharya Swami Rambhadracharya Ji, who himself is a visually impaired person and came forward to establish the University for persons with a disability named Jagadguru Rambhadracharya Handicapped University. After Uttar Pradesh, Tamilnadu and Delhi have the highest while in Lakshadweep and Ladakh there is no student enrolled in HEI while in Daman and Diu only 3 students are enrolled. These low numbers of enrolment are clearly a great matter of concern.

\section{Roadblock on the way of Inclusivity in Higher Education}

To make education accessible for all the PwD students, RPwD (2016) has increased the reservation from $4 \%$ to $5 \%$ for PwD students in HEIs it also declared that the appropriate Government and the local authorities shall endeavour that all educational institutions funded or recognised by them provide inclusive education to the children with disabilities and towards that end shall-

(i) admit them without discrimination and provide education and opportunities for sports and recreation activities equally with others;

(ii) make the building, campus, and various facilities accessible;

(iii) provide reasonable accommodation according to the individual's requirements;

(iv) provide necessary support individualised or otherwise in environments that maximise academic and social development consistent with the goal of full inclusion;

(v) ensure that the education to persons who are blind or deaf or both is imparted in the most appropriate languages and modes and means of communication;

(vi) detect specific learning disabilities in children at the earliest and take suitable pedagogical and other measures to overcome them;

(vii) monitor participation, progress in terms of attainment levels, and completion of the education in respect of every student with a disability;

(viii) provide transportation facilities to the children with disability blindness and low vision; deaf and hard of hearing; locomotor disability including cerebral palsy, leprosy cured, dwarfism, acid attack victims and muscular dystrophy; 
Besides having so many endeavours by the government side, it has been seen that the lacuna remains in the enrollment and retention of students with disabilities into higher education (Prabavathy, 2016). The lower number of enrolments of PwD students in HEI clearly shows the failure of these endeavours. Somewhere the problem lies in the implementation, proper monitoring, and regular follow-up. By keeping these things in mind the author has tried to line down some of the probable roadblocks of PwD students in HEIs below:

- Correct measurement of disability - The accurate measurement of the $\mathrm{PwD}$ people is the most important thing. Jeffery and Singh (2008) reported that the census and NSS have radically different definitions of four of the five major kinds of impairments, which explains some but not all the difference in their estimates which makes one think on the loose bases of measurement. Besides accurate recognition by definition, there is a problem of confirming by rural people specifically that one is disabled which hinders the correct measurement. It is seen that in rural India people specifically women due to stigma avoid telling the truth of disability. Mehrotra (2004) observed that rural women with disabilities may be the most likely to be overlooked. All these things make a big question mark on the reliability of the disability data.

- Neglecting PwD in National policy - PwD people are as important as the normal person of India thus their needs should also be considered seriously while framing any national policies but it has been seen that they've always given less emphasis and neglected or loosely emphasized than any other things while framing national policies. When the draft national education policy, 2019 was released it was assessed by the NCPEDP (2019), and after long inquiries, they had published its input on The draft National Education Policy wherein it points out that the draft NEP fails to meet the needs of people with disabilities. The Policy fails to make any reference to the country's legislation on disability RPwD Act 2016 instead refers to PwD 2005. It further asserted that representatives from the sector and people with disabilities have also not been consulted but their contribution has been acknowledged in Appendix VII under eminent personalities. their interactions with them reveal that they were part of no such consultation, basic structures required to make education inclusive for students with disabilities in accordance with the RPwD Act 2016, loose use of CWSN instead students with disabilities or children with disabilities as propagated by UNCRPD (United Nation Convention on the Right of Person with Disabilities) to which India is a signatory and lastly it says that home-based and open learning has been excessively relied upon in the policy. Although the New Education Policy (2020) has come now which has referenced RPwD 2016 instead of PwD 2005 like the draft policy, this also spoke very superficially of $\mathrm{PwD}$ students in the higher education section. These all things make one think whether we are really giving the $\mathrm{PwD}$ the due acknowledgement or not?

- Inability to get the disabled certificate - It is seen that to get the benefit of the reservation made for PwD students is most of the time violated as even a minute disabled person can get a disabled certificate and misused it. In this way, for the people, it is actually made not to get the advantage of it due to lack of awareness or not knowing a proper channel through where they can get this certificate. Thus this problem should be handled by the HEI by giving PwD students the needed guidance in this field especially to the people who are coming to HEI from the rural areas.

- Unaware of government programs - The biggest issue of coming PwD students in HEI is the unawareness of government-run programs which can be seen clearly in census 2011 data according to which in the rural areas, $49 \%$ of the disabled are literates while in urban areas, the percentage of literates among the disabled population is $67 \%$. Thus it can indicate the unawareness of $\mathrm{PwD}$ students about the scholarship; otherwise this number could have been much higher.

- Social stigma - Most of the PwD students reside in rural areas where the social stigma exists that what they will do by getting an education, at the end they have to face problems in getting employment anyway. Thus it is a big issue for PwD to get admission to the HEI. So even if somehow they complete the full school education, till coming to HEI they are dropping out due to this fixed stereotypical perception.

- Infrastructure - Accessibility is the biggest backbone for disabled students. According to the members of the NCPEDP, less than $1 \%$ of the country's total number of educational institutions are disabled-friendly. Most of the buildings are old thus the new norms aren't applicable to them hence it fails to fall under the disabled friendly buildings. In the AISHE (2020) report only ramps and separate toilets for females are surveyed, although that is not the only criteria to make the HEI accessible for PwD students. There should also be a survey conducted on availability of lifts, elevators, inclusive toilets, restrooms and hostel facilities for $\mathrm{PwD}$ students in all the HEI as a person having locomotor 
disability faces difficulty in the absence of such facilities. Mohanty (2015) reported that the majority of teachers $(>80 \%)$ agreed that elevators/lifts \& special; laboratories were not their institution. This clearly shows that only a handful of our HEI's are having such faculties which is a reason that a very less number of people having severe limbic damage come to the HEI and only moderate or less affected locomotor disabled students reach the HEI. Other than that it's a duty of HEI to provide assistance to visually impaired students yet it is seen to be rarely happening. Lack of inclusive toilets, restrooms, and hostel facilities are some of the major issues which should be catered and pondered upon in time if we really want to bring this section of the society into higher education.

- Attitude-related issues - It is appropriately said that the greatest barrier to inclusion is usually not architecture but attitudinal. It's often teasing and exclusion by peers. Attitude and perception of teachers towards the PwD students are equally important as any other issues. Thus awareness about their needs should be the first priority of the HEIs to train the teachers and make them aware of such things. Prabavathy (2016) in her study also finds that there is a pressing need for creating awareness and conduct of training programmes on disabilities, accessible instructional designs, and use of assistive devices for promoting effective inclusive higher education.

- Counselling of PwD students - In every college there should be mandate counselling of the $\mathrm{PwD}$ students as it is perceived that their chances of getting the job are very rare which leads to dissatisfaction and less attraction towards getting higher education. Very few self-motivated students only come to HEI fighting all the odds and uncertainty; thus in this situation it's a duty of HEI to provide enough career-related counselling as well as psychological counselling to give them relief from this sort of stress.

- Examination - Although the provision of getting extra time is there for visually impaired students yet they face difficulty in searching for the writer. In a discussion with a few visually impaired PG students of the university, it was found that they mostly relied upon the NGOs for getting the writer and any other kind of help if needed rather than on the university. Students with severe locomotor disability also find the same issue that of the visually impaired students. Thus it is the duty of the HEI to come forward for all these kinds of help as every time and in every city, it is not possible to get an NGO working for this section of society so easily.

- Curriculum - Children with physical disabilities have normal intelligence and don't need any special curriculum. What they need from us are just acceptance and a little adjustment. The curriculum for visually impaired as well as speech impaired students needs to be such that it should get ample opportunity to include the active pedagogical method. But it is seen that in most of the HEI's lecture method is majorly followed as teaching methodology which is surely unable to cater to the need of students with visual and hearing impairments although locomotor disabled students don't really get affected by this much.

- Employment issues: The Census 2011 highlighted that nearly one-third of the total disabled persons are working. This means two third people are not in employment or working. Most of them are cultivators or in agriculture, 23 and $31 \%$ respectively. They see a better opportunity in skill-based work so they better go for vocational training than the normal courses after school education so that at least that kind of job can be accessible but here the question comes that what if someone wants to go to a higher level like IAS or any other service officer job. They either have to compromise or think of some other job. Very few can only come to this level by fighting all the odds. TOI reported that Several PwDs whose exam of crack civil services are routinely rejected with the government claiming there is no suitable service for them (Muralidharan, 2013) such types of things prove to be really disappointing.

- Support centre - In every college and university there should be an accessible support centre for the PWD students but it is seen that very rare HEI's are having a separate support centre specifically established for the PwD students. As in the post-secondary period, they face major challenges and at this time they don't have an option like they had in school where they can opt for special education centres, in higher education they have to come to regular classes where all the normal treatment is provided to them. This is the reason that in the initial days of college/university the students usually get frustrated to handle all the stress and eventually drop out in the absence of proper support and counselling. That is why effort should be given in this area also.

\section{Suggestions}

After analyzing all these issues and problems some of the suggestions have been line down by the author to overcome the shortness of enrolments of PwD students in higher education which are as follows:

- First of all, the correct and more detailed measurement of this section of society is needed so that more robust and focused solutions can be provided. 
- Proper implementation of national-level policies and their follow-up should also be taken into consideration. As it has been seen that so many programs have been made for them but when it comes to implementation and follow up, it is rarely practiced or done.

- Most of the PwD people live in rural areas for whom a proper awareness program with respect to opportunity, employability, scholarship schemes, disabled certificates and various other important matters should be organised where all the doubts and the social stigma can be removed.

- Assurance of disabled friendly buildings as soon as possible in all the HEIs should be the first priority of the GOI for which all the necessary steps should be taken. It can only be done if a detailed survey of the HEI is done regarding all the infrastructure facilities, not only a few like ramps but the availability of lifts, elevators, inclusive toilets, restrooms, and hostel facilities should be reported to get a clear picture of inclusiveness of HEIs.

- Interactive teaching method or disabled centric teaching approach should be used then only using the age-old lecture method so that every student need can be catered upon. For visually impaired students, Braille script should be provided so that they can become independent, and for speech and locomotor disabled persons the involvement can be assured as they don't need a separated learning pedagogy just assurance of acceptance is enough for them.

- In technical and professional courses the medium of instruction is English which the $\mathrm{PwD}$ students find tough to cope up with hence some kind of remedial or pre-preparation kind of arrangement should be done by these institutions.

- Although NGOs are working for the welfare of PwD students, the initiative of the government also cannot be ignored. Mostly because of lack of information PwD students have to suffer thus detailed information through orientation and awareness programs should be given to the university students or at the end of higher secondary schools. There are various national portals that can be useful for the $\mathrm{PwD}$ students like www.swavlambancard.gov.in for unique ID cards, disabilityaffairs.gov.in for various schemes, disabled certificate forms, and scholarship related information www.nhfdc.nic.in, www.india.gov.in, thenationaltrust. gov.in, etc., these all things should be discussed in those orientation programs and how they can use it.

- In the awareness program conducted at the HEIs, even the success stories should be presented to raise the motivation of students so that they can feel that they are no lesser than the ordinary people and have the same capacity to perform and achieve all the things in all the field whether it is from sports or cracking India's highest level examination IAS.

- Equal participation is assured in the co-curricular activities as well as of the PwD students.

\section{Conclusion}

It can be said that a concerted effort is needed by the government to make our educational institutions and workplaces more inclusive. Although the number of PwD students has increased from 2019 to 2020. The increase seems to be very minute and insignificant which drags the attention towards this section of society. There should be some strict guidelines as well as training for teachers initiated by the GOI. Proper counselling centres and support centres should be made compulsory to open up in HEIs so that more and more students can come to the HEI. Implementation, as well as regular follow-up of the programs, should be checked. If we assure all these things and the importance of $\mathrm{PwD}$ students then only their full support and participation can be assured hence all the effort should be taken into this direction. The more they will feel secure and assisted the more participation can be assured from them.

\section{References}

GOI (2011). Census of India 2011: Data on Disability, Government of India, Office of Registrar General \& Census Commissioner, New Delhi, India. Retrieved from: censusindia.gov.in

Jeffery, R., \& Singal, N. (2008). Measuring Disability in India. Economic and Political Weekly, 43(12/13), 22-24.

Mehortra, N. (2004). Women, Disability and Social Support in Rural Haryana, Economic and Political Weekly, 39(52/56), 40-44.

MHRD (2019). All India Survey on Higher Education. Ministry of Human Resource Development, Department of Higher Education, New Delhi.

MHRD (2020). All India Survey on Higher Education. Ministry of Human Resource Development, Department of Higher Education, New Delhi.

MHRD (2020). National Education Policy 2020. Ministry of Human Resource Development, New Delhi, India.

Mohanty, S. P., \& Jena, S. S. (2015). Perception of teachers about educational provisions for students with 
disability in higher education institution. Pedagogy of Learning, 1(4), 92-104.

Muralidharan (2019, July 30). Access Denied. The Indian Express. Retrieved from: https://indianexpress.com/ article/opinion/columns/india-national-educationpolicy-unesco-children-with-disabilities-right-toeducation-5861820/

Nagarajan, R. (2013, December 2). Disabled people cleared UPSC but wait for the service allocation, Times of India. Retrieved from: https://timesofindia.indiatimes. $\mathrm{com} /$ india/disabled-people-clear-upsc-but-wait-forservice-allocation/articleshow/26713017.cms

NCPEDP (2019). Gaps in DNEP vis-à-vis people with disabilities and corresponding inputs. National Centre for Promotion of Employment of Disabled People (NCPEDP) and National Disability Network. Retrieved from: https://ncpedp.org/documents/ Inputs $\% 20$ on $\% 20$ The $\% 20$ Draft $\% 20$ National $\% 20$ Education\%20Policy\%202019.pdf

Prabavathy, M. (2016). Awareness and Attitude of Faculty Members towards Inclusion of Students with Disabilities in Higher Education. Imperial Journal of Interdisciplinary Research (IJIR), 2(9), 749-755.

RPwD (2016). The Right of Persons with Disabilities Act, 2016. Ministry of Law and Justice, Government of India, New Delhi, India. Retrieved from: http://www. upfcindia.com/documents/rpwd_101017.pdf

\section{苟 CHITKARA}

\section{Issues and Ideas in Education}

Chitkara University, Saraswati Kendra, SCO 160-161, Sector 9-C, Chandigarh, 160009, India

Copyright: [C 2021 Aditi Pandey] This is an Open Access article published in Issues and Ideas in Education (Issues Ideas Educ.) by Chitkara University Publications. It is published with a Creative Commons AttributionCC-BY 4.0 International License. This license permits unrestricted use, distribution, and reproduction in any medium, provided the original author and source are credited. 